\title{
Maps in Citizen Science: A Preliminary Analysis of Use and User Issues
}

\author{
Artemis Skarlatidou $^{\mathrm{a}, *}$ and Marcos Moreu ${ }^{\mathrm{a}}$, \\ ${ }^{a}$ University College London, Department of Geography, a.skarlatidou@ucl.ac.uk,marcos.moreu.18@ucl.ac.uk, \\ * Corresponding author
}

Keywords: Citizen Science, Usability, Maps

\begin{abstract}
:
Citizen Science involves a collaboration or partnership between scientists and amateur volunteers, which may take various forms; from simple data collection to a close collaboration where both parts jointly define their aims, methodologies and analysis approaches in the scientific endeavour. Although citizen science has existed for more than two centuries (Silvertown, 2009), the widespread use of information and communication technology (ICT) now plays a significant role in the way citizen science is currently shaped and utilised. At present, there are hundreds of citizen science applications available which engage thousands of volunteers in the disciplines of astronomy, environmental conservation, biology, marine science, geography and many others. A relatively recent analysis of 388 citizen science projects revealed that they have been used to engage 1.3 million volunteers, contributing up to US\$2.5 billion in-kind annually (Theobald et al. 2015).
\end{abstract}

Web 2.0 and its associated technologies, which have existed for almost 15 years now, have enabled the development of websites which supported content generation by their end users (aka crowdsourcing; Howe, 2008) and multiple interactions amongst them. Examples include web-based communities, social-networking sites, wikis, mashups, and others (Batty et al., 2010). In this context the term 'Neogeography' was coined (Eisnor, 2006) and since then it has been used within the geographic and cartographic circles to describe the multi-directional generation of geospatial contents and interactions, which enables non-GIS professionals to create and share maps and other geographic information online "on their own terms" simply using the "elements of an existing toolset" (Eisnor, 2006). Map mashups started to not only be used for disseminating spatial information to a wider user audience, but applications have been created which enabled the crowdsourcing of geographic information for the production of geospatial knowledge; a trend, which is also known under the term Volunteered Geographic Information (Goodchild, 2007). OpenStreetMap (OSM) is perhaps one of the earliest examples that the literature cites to demonstrate how harnessing the power of the crowds for the collection of geographic information can result in the creation of a free, open source of map of the world (Goodchild, 2007; Haklay et al., 2008; Batty et al., 2010).

We argue in this paper that the above developments from the geospatial context have massively contributed to the current state of citizen science. While interactive web maps made their appearance as mainly "way-finding" tools (Skarlatidou and Haklay, 2006), they quickly became part of digital interactions in a much broader context and they are currently a basic component of most citizen science projects. The relevance and significance of space has been fully exploited by technological features such as geotagging, GPS-enabled mobile devices fully integrated with other sensors, which has made the collection and sharing of data much easier (Haklay, 2013). Sinton (2018) argues that it is such the power of maps in citizen science that "it would be difficult to pursue a project in biological conservation, for example, without incorporating mapping". The breadth of citizen science applications is so wide that we observe an extremely wide range of potential users, with very different skill sets, backgrounds, literacy levels and user needs.

The rise of public participation in citizen science has been accompanied with the realisation that there is limited research about how participants interact with these technologies and what are their user experiences. Preece (2016), amongst others, highlights the need for a greater collaboration between Human-Computer Interaction (HCI) and citizen science communities as the former can "dramatically increase what they [citizen scientists] do and how they do it" (p.585). While these arguments refer to the broader field of citizen science, it is well known in the geospatial community from our experiences in other contexts (e.g. participatory GIS in policy-making), that non-expert interaction with mapping interfaces increases complexity (Skarlatidou et al., 2013). Batty et al. (2010) further mention that such applications are developed based on methods which are "intuitive, expressive, personal, absurd, artistic or maybe just simply idiosyncratic applications of 'real' geographic techniques" and they do not necessarily "conform to the protocols of professional practice" (p1) which further creates interaction barriers and concerns for the end user. It is our aim in this study to uncover some of these barriers and improve our understanding about how web maps are currently utilised in citizen science and how well they incorporate use and user issues in their design using a HCI-driven approach.

Our preliminary analysis includes an initial inspection of one of the most popular multi-project platforms, SciStarter (SciSarter.com), to identify and list all citizen science applications which have a web-based mapping component. Two evaluators went through 1,467 projects that are currently provided via SciStarter, using two different search approaches. This resulted in a detailed review of 345 applications, which were inspected for the following attributes: area covered; basemaps; mapping API; map size; basic functionality such as zooming, panning, search, 
filtering; visualisation of geographical features (e.g. point clustering, data aggregation); functionality for adding data (geographical data as well as text, photographs and other); registration/login; overall look and feel. This preliminary analysis provided a general understanding of the current state of web-based mapping in citizen science and we detected four interactivity levels, starting from low complexity - where desktop maps are simply used to visualise contributed data together with comments or photographs - to more complex mapping, which enables volunteers to edit features and which resembles geospatial editing in a GIS environment. In the next step, two applications from each of the first three levels were selected (Wildlife Connectivity Study; CyanoTracker; Kissing Bugs \& Chagas Disease; Tomnod; iMapInvasives; Curio) and one from the last (OpenStreetMap) for further evaluation using the methods of heuristic evaluation (Nielsen, 1993) and cognitive walkthrough (Wharton et al., 1994).

The heuristic evaluation was based on the guidelines which have been recently proposed by Skarlatidou et al. (in press) and which were developed based on an extensive systematic literature review and user testing to identify and provide a framework of user needs and requirements in citizen science. To effectively capture the spatial component we included a set of guidelines which were proposed for improving usability and trust in non-experts interactions with webmapping for decision-making purposes (Skarlatidou et al., 2013). To improve subjectivity and eliminate any potential bias, all three authors carried out the heuristic evaluation on all seven applications. To better understand use and user issues, which are relevant for each application we built up a persona, which we used in cognitive walkthrough sessions, which were carried out also by all three evaluators using all seven applications.

Web-based mapping in citizen science can be used to serve the following five main functions; a. visualise contributed data; b. enable volunteers to make a new contribution; c. acknowledge volunteers' effort; d. support spatial analysis; e. create a sense of community. Using this classification, we provide insight into the characteristics (technological, interface and user-based) that are associated with each one of these functions at four interaction levels. We also report on the most severely ranked usability issues, which are common across all interfaces and which refer to the overall interface design (e.g. providing a menu item to link to the mapping interface and making clear whether a mobile version is supported as well as how it is different in its functionality from the web mapping interface). Although we acknowledge that citizens science applications do not need to support all five functions (or they can do so without using maps), we critically review the usability problems and user issues which are specific to each one of the proposed functions and which prevent the application from its successful utilisation and in most cases - as we report - leads to a complete system failure in serving that specific function. With our results and preliminary analysis not only we provide the first critical insight into the use of web maps in citizen science to support the design and development of more effective interfaces but we further set the landscape and explore a set of questions that may be used to inspire future research in this area.

\section{References}

Batty, M., Hudson-Smith, A., Milton, R. and Crooks, A. (2010) Map mashups, Web 2.0 and the GIS revolution, Annals of GIS, 16:1, 1-13.

Eisnor, D. (2006). What is neogeography anyway? [online]

http://platial.typepad.com/news/2006/05/what_is_neogeog.html [accessed 13 Dec 2018]

Goodchild, M. F. (2007). Citizens as sensors: The world of volunteered geography. GeoJournal, 69, 211-221.

Haklay, M., Singleton, A. D., \& Parker, C. (2008). Web mapping 2.0: The neogeography of the geospatial

Internet. Geography Compass, 2, 2011-2039.

Haklay, M. (2013). Citizen Science and Volunteered Geographic Information - overview and typology of participation. In: Sui, D.Z., Elwood, S. and M.F. Goodchild (eds.), 2013. Crowdsourcing Geographic Knowledge: Volunteered Geographic Information (VGI) in Theory and Practice. Berlin: Springer. pp 105-122 DOI: 10.1007/97894-007-4587-2 7

Howe, J. (2008). Crowdsourcing: Why the power of the crowd is driving the future of business. New York:

Crown Business.

Nielsen, J. (1993). Usability Engineering. New York: Academic Press.

Preece, J. (2016). Citizen Science: New Research Challenges for Human-Computer Interaction. International Journal of Human-Computer Interaction, 32(8), 585-612.

Silvertown, J. (2009). A new dawn for Citizen Science. Trends in Ecology \& Evolution 24(9), 467-47.

Sinton (2018) Where are we with Citizen Science Mapping Apps today? [online] https://www.directionsmag.com/article/7515 [accessed 18 Dec 2018].

Skarlatidou, A. and Haklay, M. (2006). Public Web Mapping: preliminary usability evaluation, Proceedings of GISRUK 2006, Nottingham, UK.

Skarlatidou, A., Cheng, T., Haklay, M. (2013). Guidelines for tsut interface design or public engagement Web GIS. International Journal of Geographic Information Science, 27 (8), 1668-1687.

Skarlatidou, A., Hamilton, A., Vitos, M., Haklay, M. (in press). What do volunteers want from citizen science technologies? A systematic literature review and best practice guidelines. Journal of Science Communication.

Theobald, E.J., Ettinger, A.K., Burgess, H.K. et al. (2015). Global Change and local solutions. Biological Conservation, 181, 236-244.

Wharton, C., Rieman, J., Lewis, C., Polson, P.G. (1994). The cognitive Walkthrough method: A Practitioner's Guide. In: Nielsen, J. and Mack., R (eds). Usability Inspection Methods. Wiley, 105-140 